\title{
Investigating the financial crisis of the Tehran Stock Exchange using the entropy method of transfer and comparing it with the US financial market
}

\section{Arefeh Mohaghegh}

Department of Accounting, Kish International Branch, Islamic Azad University, Kish Island, Iran. (Email: mohaghegh.arefeh@gmail.com)

\section{Mohsen Hamidian*}

*Corresponding Author, Associate Prof., Department of Accounting, Islamic Azad University, South Tehran Branch, Tehran, Iran. (Email: m_hamidian@azad.ac.ir)

\section{Seyed Ali Hosseiny Esfidvajani}

Assistant Prof., Department of Physics, Shahid Beheshti University, GE Even, Tehran, Iran. (Email: al_hosseiny@sbu.ac.ir)

\section{Gholamreza Jafari}

Prof., Department of Physics, Shahid Beheshti University, GE Even, Tehran, Iran. (Email: g_jafari@sbu.ac.ir)

Document Type: Original Article

Received: 2020/12/15
Accepted: 2021/03/13
2021, Vol. 5, No. 3. 1-16.

Published: 2021/06/13

\begin{abstract}
This work aims to analyze the relationship between stocks in the financial market of the Tehran Stock Exchange embedded in their transfer entropy. In this regard, the behavior of the transfer entropy between indices of 180 corporations of the Tehran Stock Exchange has been studied. Then the footprint of crises of the market has been searched in the trends of the transfer entropy. The result has been compared with the result of the analysis imposed on the stocks included in the Dow Jones industrial index in the stock exchanges of the United States. In order to investigate the financial crisis of the Tehran Stock Exchange, the stock price data of 180 companies in this market that were active in the period from 2008 to 2018 are analyzed. It is observed that the average pairwise transfer entropy of indices in the Dow Jones group declines
\end{abstract}


over the financial crises in the United States. In Iran, despite the United States, the financial crises have not left a footprint in the pairwise transfer entropy over the studied period. Such an observation suggests future studies on the pairwise and possibly collective behaviors of indices in Iran and the United States.

Keywords: Financial Crisis, Tehran Stock Exchange, Transfer Entropy, Dow Jones

Thematic classification: G35, G31

DOI: 10.30699/IJF.2021.262236.1183

Publisher: Iran Finance Association Copyright: author(s)

Type of License: Creative Commons License (CC-BY 4.0)

\section{Introduction}

In general, a situation in which a noticeable portion of financial assets loses a major part of those values is called a financial crisis. A wide variety of endogenous and exogenous shocks or imbalances may lead to financialeconomic crises (Hasanzade and Kiavand, 2010). According to Reinhart and Rogoff (2009), financial crises are an equal opportunity-threat and can have internal or external origins and emanate from the private or public sectors.

In pre-capitalist societies, crises usually were caused by external factors such as floods, epidemics, famines, and droughts, but in a market-based society (capitalist system), usually, a series of factors within the system act in such a way that disrupts the functioning of the whole system and make it heterogeneous. The market system is constantly vulnerable and generally capable of crisis because the inherent essence of the system is based on contradiction and imbalance.

Studying the relationship between indices in the financial market and the possibility of any predication such as predication of crisis is has been a hot issue in economic literature. Fama believes that markets are efficient which leads to the belief that stocks usually fluctuate in an uncorrelated random stochastic manner. As a result, extracting meaningful information from the history of indices to predict the future is almost impossible. Despite early approval of the market efficiency hypothesis, the concept has been challenged in future works, see for example

2. Mantegna, R. N. \& Stanley, 2000, Lo and Mackinlay 1990, Jegadeesh, N. \& Titman 1993, and reference therein. 
The structure of information of pairwise interactions can be analyzed through the transfer of entropy. The entropy of information was introduced by Shanonn (1948). Transfer Entropy has been introduced by Schreiber (2000) to grab entropy of information to address Winer causal relation (Winer 1949).

The entropy of information has applied to study Iran Stock Exchange by Ossolian et al where the causality relation between indices has been analyzed (Ossolian, Hosseiny, Bagheri). In this work, we measure the transfer of entropy between stock indices in Iran and compare it with indices of Dow Jones from the US.

Considering the presented materials, the main question of this research is whether it is possible to estimate the financial crisis of the Tehran Stock Exchange market by using the transfer entropy method and then compare it with the Dow Jones industrial group from the US financial market.

\section{Research Background}

Static et al. (2016), using the time-dependent block entropy method, investigated the effects of financial crises in foreign exchange markets and the evolution of entropy for different exchange rates has been measured. The results show that financial crises are associated with a significant increase in exchange rate entropy, indicating instability in the dynamics of the foreign exchange market. In a study, Rommel (2017) analyzed 153 companies listed on the Nasdaq Stock Exchange, and using the transfer entropy, compared the flow of information between different industries. The results have shown that the durable industry, consumer and financial industries provide the major share of information about the economy as a whole. Using the one-day delay, it was found that the introduction of a delay variable significantly increases the transfer entropy in all industries except energy, while technology has the highest increase (103\%) compared to the average (28\%). Also, after one day of delay, it was shown that the additional delay generally reduces entropy transfer, but not uniformly, indicating that the movements are more influenced by two-day trends. Using network entropy, Lee and Park (2019) have measured the diversity of highly connected financial networks. Due to the change in the time of network entropy, the international diversity of the global financial network made up of foreign claims of international banks has declined since the 2008-2007 financial crisis, while foreign claims among the 20 reporting countries are mostly focused on the main countries. This change 
is clearly seen by the network entropy due to the unprecedented drop in measurement. The results show that network entropy has promising potential in the financial market. Arab Salehi et al. (2017) have studied the effect of the global financial crisis on earnings management in companies listed on the Tehran Stock Exchange. To test these effects, 130 companies listed on the Tehran Stock Exchange were studied; in this study, earnings management indicators have been measured and expressed by determining the amount of earnings smoothing and the modified Jones model. The findings indicate that the rate of profit management in companies listed on the Tehran Stock Exchange has decreased during the years of the global financial crisis. Abdollahzadeh et al. (2015) have investigated the effect of entropy of liquidity and leverage ratios on the identification of companies suspected of fraud in the financial reporting of the Tehran Stock Exchange. To this end, the changes in liquidity and leverage ratios items are measured based on the entropy formula and then the effect of these changes on the likelihood of fraudulent reporting is investigated. The results showed the significance of the tested models and in the two hypotheses tested for entropy, the ratios of total debt, operating funds to debt were significant and other tested variables were rejected in the hypotheses. Bayani and Mohammadi (2019) aimed to determine the factors affecting financial crises in the Iranian economy by defining uncertainty in crisis models and with a conventional approach to Bayesian averaging. In this study, 62 variables affecting the financial crisis were included in the model, and finally, using the Bayesian averaging model approach, 12 non-fragile variables affecting the financial crisis were identified which include: budget deficit or surplus; deviation of the informal exchange rate from formal; inflation; the ratio of foreign debt to foreign assets of the central bank; increasing money ratio (liquidity / monetary base); export to GDP ratio; the ratio of imports to GDP; the ratio of government spending to GDP; budget deficit to GDP; liquidity ratio to foreign assets of the central bank; the growth rate of loans to the private sector and the square of the inflation rate. Given the output of the results, it can be said that the financial crisis index in the Iranian economy is a multidimensional problem; because variables related to fiscal policy, monetary policy and exchange rate policy affect this index. Jafari, Namaki et al. In 2013, compared emerging and mature markets in times of crisis, and in a non-extensive statistical approach, the results obtained in the study indicated an increase in structural entropy in times of crisis. 


\section{Concepts of entropy and transition entropy}

Entropy is one of the most fascinating and powerful concepts in the history of science, engineering and information. This concept has been proposed twice, a century apart. In the 19th century, Rudolf Clausius introduced it in thermodynamics. Nearly a century later, Claude Shannon introduced it for communication and information theory. Entropy, as a thermodynamic concept, is a measure of the disorder of a system. The theory of transfer entropy was presented by Schreiber in the context of information theory. transfer entropy not only covers some features of mutual information but also expresses the dynamics of the transferred information. To calculate the exchange of information between two systems separately and in a directional way, the transfer entropy takes into account the minimum necessary assumptions about system dynamics. transfer entropy is a statistical index used to measure information shifted between random variables (Schreiber-Thomas, 2000). The transfer entropy of information is defined by the following formula:

$$
\mathrm{T}_{\mathrm{I} \rightarrow \mathrm{J}}=\sum \mathrm{P}\left(\mathrm{i}_{\mathrm{n}+1}, \mathrm{i}_{\mathrm{n}}^{\mathrm{k}}, \mathrm{j}_{\mathrm{n}}\right) \log \frac{\mathrm{P}\left(\mathrm{i}_{\mathrm{n}+1} \mid \mathrm{i}_{\mathrm{n}}^{\mathrm{k}}, \mathrm{j}_{\mathrm{n}}\right)}{\mathrm{P}\left(\mathrm{i}_{\mathrm{n}+1} \mid \mathrm{i}_{\mathrm{n}}^{\mathrm{k}}\right)}
$$

\section{Dow Jones Index}

The Dow Jones Industrial Average is a weighted price index of 30 large companies in the US stock exchanges. The companies belong to various sectors including materials, consumer goods, finance, healthcare, industry, oil and gas, technology, telecommunications, and public services. However, the index can be subdivided into sub-indices to facilitate performance monitoring. These indicators are based on the fact that companies are considered high value, medium value or low value. High-volume, high-value stocks make up 70 per cent of the index, which means the majority. Companies within the Dow Jones Industrial Average are constantly changing. The last company to be added to this number was Cisco in June 2009. In addition to Cisco, only six companies have been added in the last ten years: Bank of America (2008), Choron (2008), Craft (2008), Pfizer (2004), Verizon (2004) and Trolls Insurance (2009). We consider companies of this group as a sample of the US stock exchange.

\section{Methodology}

The present study is applied in terms of purpose and nature, it is an exploratory study that is in the field of post-event studies using past information and based on real information published by the Tehran Stock Exchange (Total Exchange) and the Central Bank of the Islamic Republic of Iran (inflation) and data obtained from the US Dow Jones index. Companies listed on the Tehran Stock 
Exchange and OTC and the period covered by the research is 11 years and focuses on the years 2009 to 1397.

\section{The fundamental concepts of transition entropy}

All Shannon information tools can be expressed by the linear combination of entropies. If we define the entropy of a random variable $\mathrm{X}$ as $\mathrm{H}(\mathrm{X})$, we will have the following relation:

$H(x)=-\sum_{x} p(x) \log (p(x))$

where $\mathrm{p}(\mathrm{x})$ is a function of the probability distribution of each random variable and the sum is over all the states that the random variable can adopt. The base of the logarithm of any real number can be greater than 1 . In general, if we assume the base of the logarithm $\alpha$, we can calculate the entropy $\mathrm{H}(\mathrm{x}) \alpha$. If $\alpha=2$, it will be the unit entropy of the bit and if $\alpha=\mathrm{e}$, it will be the unit entropy of 2. In information theory, it is common to base the logarithm on $\alpha=$ 2.

If $g(x)$ is an arbitrary function of the random variable $X$, the expected value of $\mathrm{g}(\mathrm{x})$ is calculated as follows:

$E(g(x))=-\sum_{x} p(x) p(x)$

Therefore, the entropy can be written as follows:

$H(x)=-E(\log (p(x)))$

The entropy $H(x)$ of the random variable $X$ is a function of $p(x)$ that measures the average of the information that $\mathrm{X}$ contains. It should be noted that $\mathrm{H}(\mathrm{x})$ is related only to $\mathrm{p}(\mathrm{x})$ and has nothing to do with $\mathrm{X}$ (state values).

\section{Data sorting and preprocessing}

The present study used the data related to the stock prices of 180 companies listed on the Tehran Stock Exchange in the period from 2008 to 2018 and also the data of the United States' Dow Jones industrial group from 1991 to 2019. The data are not directly usable and need to be modified. It should be noted that firstly companies that had an active presence in the market in all the mentioned period were considered. Secondly, there are working days on which all companies are present at the same time. Thirdly, if for several companies on some days a number is not recorded as a price, instead it is considered a number that is obtained by interpolation or averaging between the price of the day before and after. 


\section{Calculation of the adjacency matrix}

After sorting the market data, the adjacency matrix should be calculated. In fact, by calculating this matrix, an attempt is made to provide a graphical model to examine the relationship between market companies. Adjacency matrix elements are the transfer entropy for two companies in the market, the number of which actually determines the amount of information transfer from company $\mathrm{i}$ to company $\mathrm{j}$. In other words, the existence of a number between 0 and 1 in each of the calculations related to the relationship between two companies in the adjacency matrix indicates the existence of a direct relationship between two companies in the market and the size of that number indicates the size and intensity of this relationship. The adjacency matrix is not necessarily symmetric in the sense that the amount of information transmitted from company $\mathrm{i}$ to company $\mathrm{j}$ is different from its inverse.

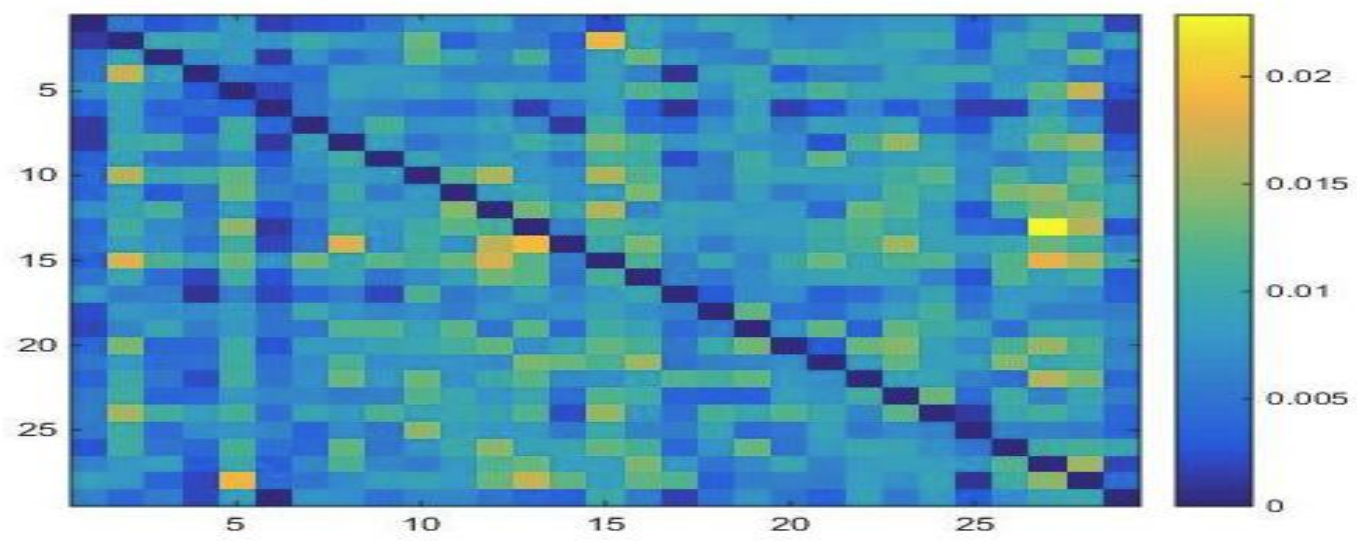

Figure 1. Adjacency matrix obtained from the transition entropy in the US Dow Jones group with 30 companies

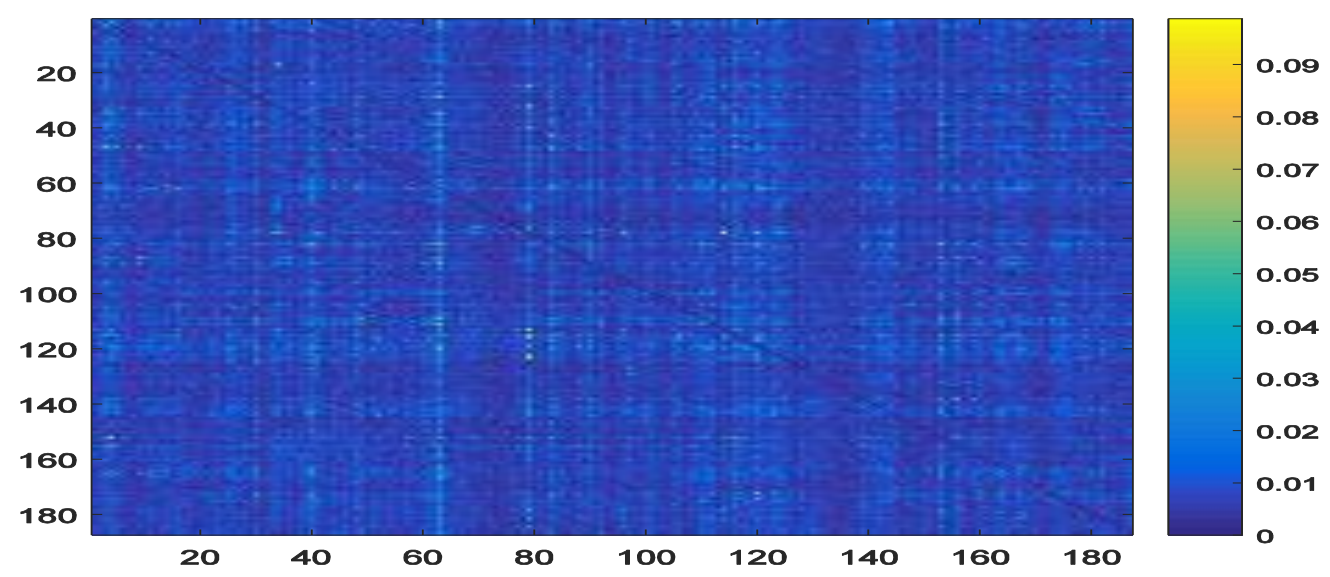

Figure 2. Adjacency matrix obtained from transfer entropy in Tehran Stock Exchange 


\section{Calculating the transfer entropy of corporate price index data}

First, we decompress the data related to the companies' price index using the logarithmic return method. To do this, considering that the time scale of the data is daily, we divide the price of each day by the previous day and take the logarithm. By doing this, we will eliminate the general trend of the index and we will have only daily fluctuations. Here, we consider the range to be 3 , which is equivalent to the price index either going up or down or staying in the current price state. If we consider a suitable partition for the data, the transfer entropy will be a descending function with respect to the variable $\mathrm{k}$. This is because, in natural processes, memory loss occurs with increasing time latency in the data. Here, we assume that when transferring information from Company $\mathrm{Y}$ to Company $\mathrm{X}$ is calculated, the effects of Company $\mathrm{X}$ itself should not be included in this calculation. With this assumption, it is better to consider the variable $\mathrm{K}$ as large as possible so that each company does not receive information from itself. But the problem is that in calculating the time series and delayed distribution function, we encounter the problem of finite size, which affects the results. To solve this problem, we construct a time series with delay $\mathrm{k}$ from each time series of each company and calculate the amount of mutual information for these two-time series.

$$
M_{I J}(\tau)=\sum p\left(i_{n}, j_{n-\tau}\right) \log \frac{p\left(i_{n}, j_{n-\tau}\right)}{p(i) p(j)}
$$

In the following figure, we plotted the reciprocal information for one of the companies in terms of $\mathrm{k}$. As expected, the resulting graph became a descending function of the time delay $\mathrm{k}$. Because with increasing time delay, the amount of data transfer decreases or in other words, the system memory decreases. Therefore, according to the diagram, we consider the desired amount of time delay as the first place where the reciprocal information is zero or has a local minimum. In this way, we calculate the optimal amount of time delay for each company.

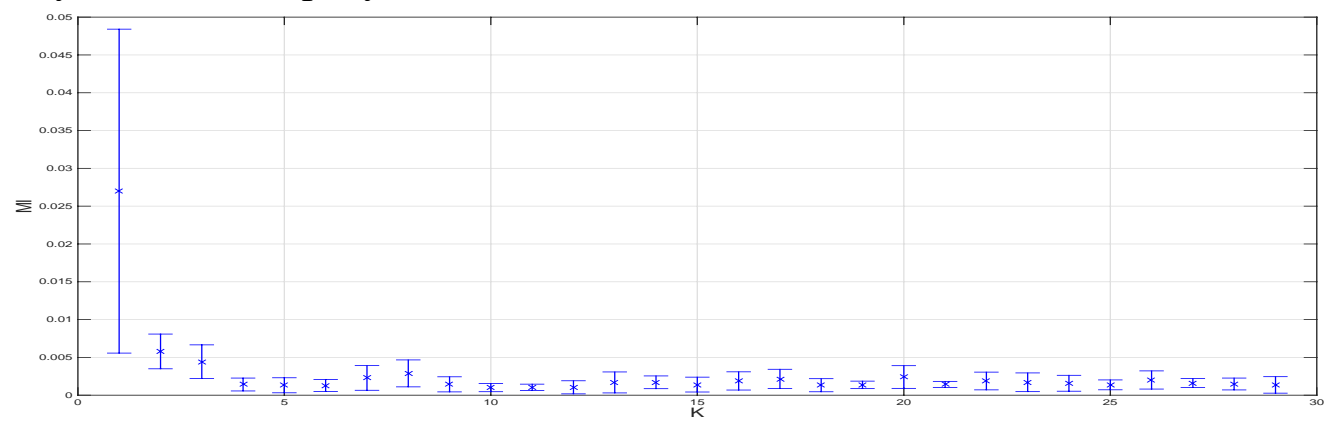

Figure 3. Mutual information for one of the companies 
$\mathrm{W}$, which is actually called the window length, can be considered as the scale length of the system in which there is meaningful information. Different window lengths can be considered as a result of which the amount of information transmitted between companies varies. The appropriate window length is considered to be where the most information is transmitted. The information transferred actually refers to the information exchanged between companies. The window length represents a scale of the system in which there is significant information. To calculate its length, we consider a window that transmits the maximum amount of information. It should be noted that the meaning of the window is the time periods defined in the diagrams. It is observed that, in Tehran Stock Exchange, as the length of the window increases, the transmitted information first increases and then decreases. The output also shows the peak of the graph that occurred during the seventy windows. This means that the maximum amount of information is transferred between companies in the stock market on a 70-day scale. While the optimal window or scale for maximizing data transfer in the US Dow Jones group was 200 days.

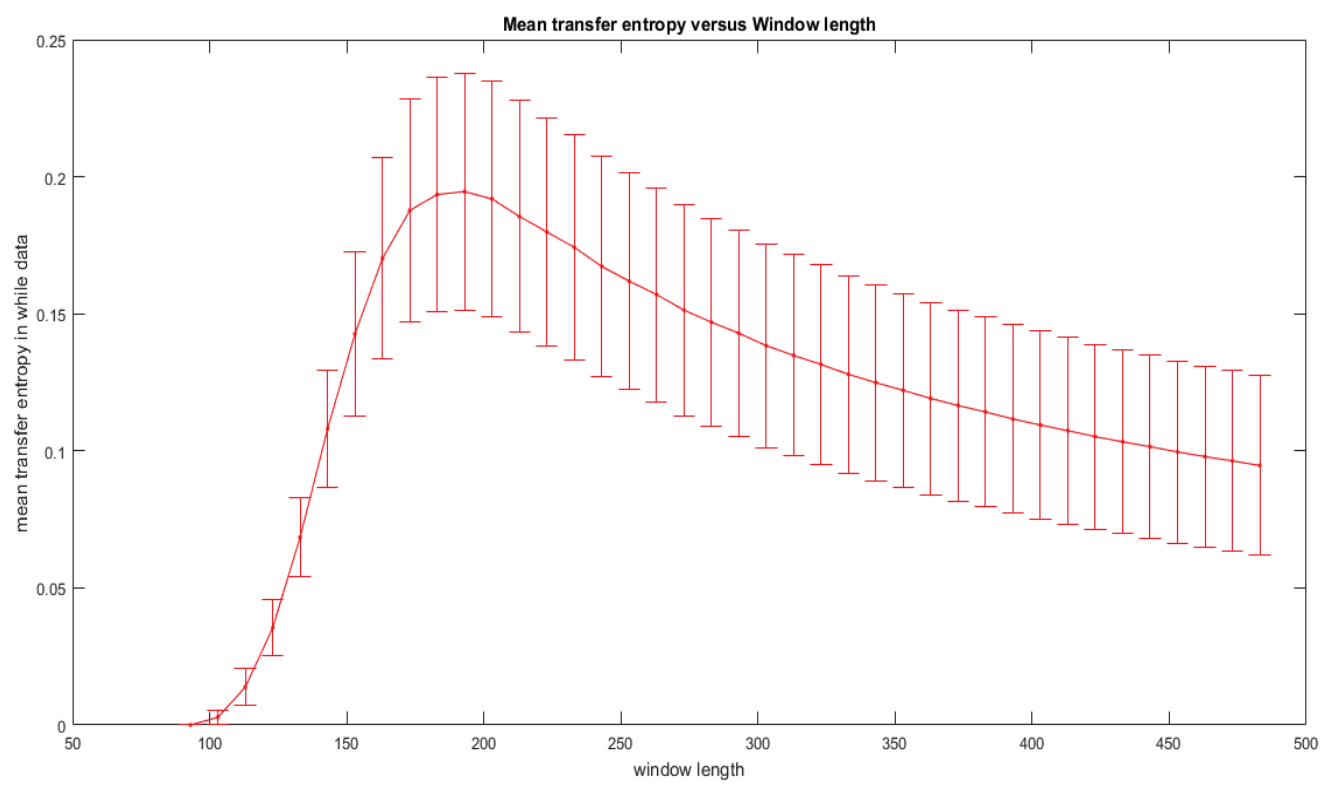

Figure 4. Average data transfer for 30 Dow Jones group companies 


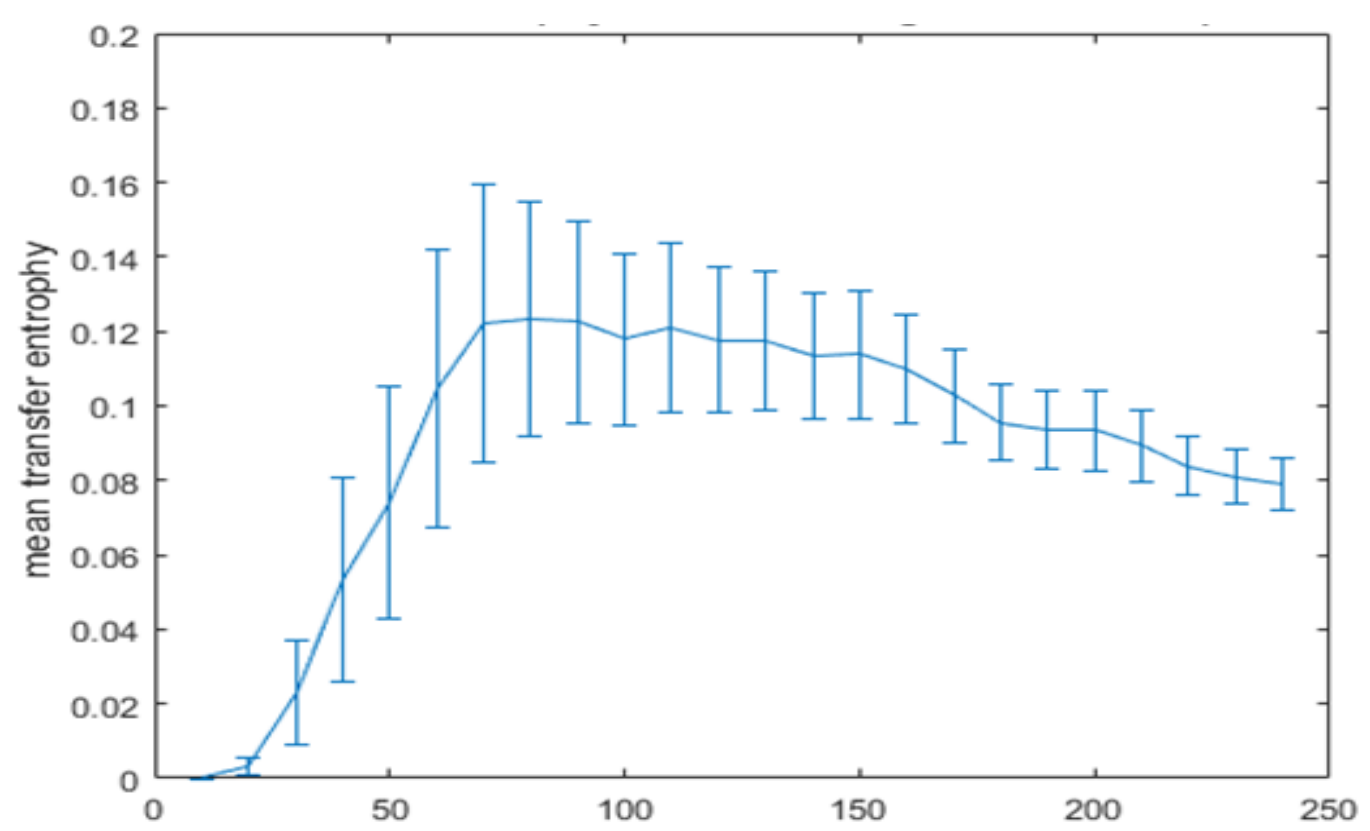

Figure 5. Average transfer of information transferred to companies of Tehran Stock Exchange

Therefore, the time scale of seventy days is considered as the optimal window length for calculating the adjacency matrix in Tehran Stock Exchange. So far, by determining the variables of transfer entropy, i.e. k, 1 and w, a significant number can be obtained for the transfer entropy, or in other words, the amount of information transferred over time. By calculating the adjacency matrix over a period of seventy days and averaging all the data, it is possible to obtain the average of the seventy-day information of the Tehran Stock Exchange, which is displayed on the last day of the window. This means that this information is related to the last seventy days. By moving this seventy-day window in series with every step equal to the size of a day, a new series is obtained, where each point is the average of the information transmitted for the past seventy days. 


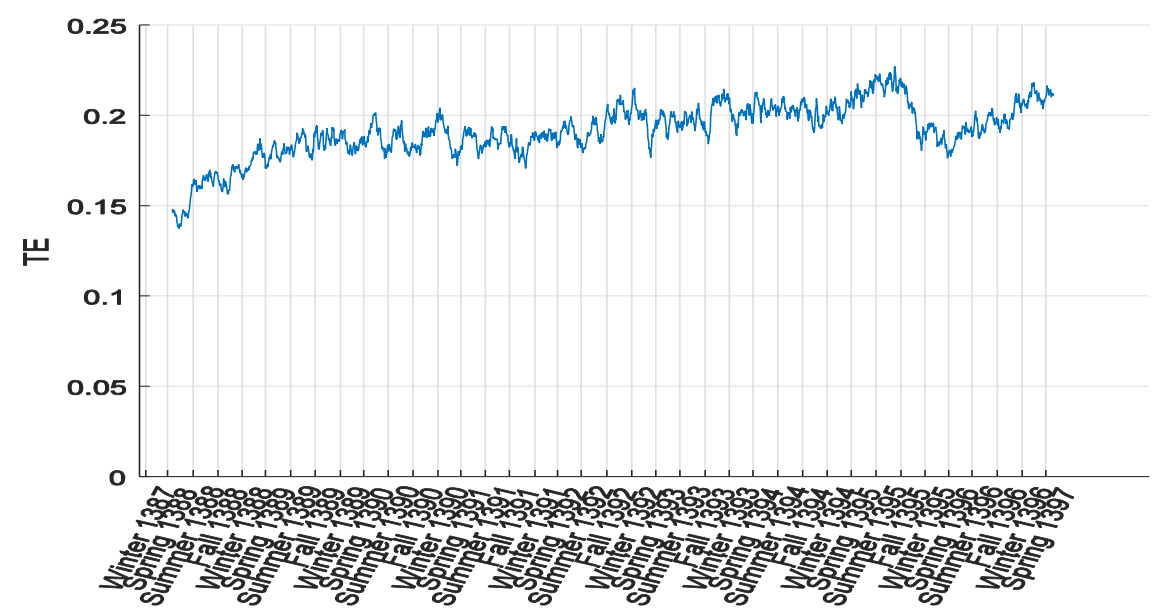

Figure 6. Average transfer entropy or average information transferred 180 companies in Tehran Stock Exchange

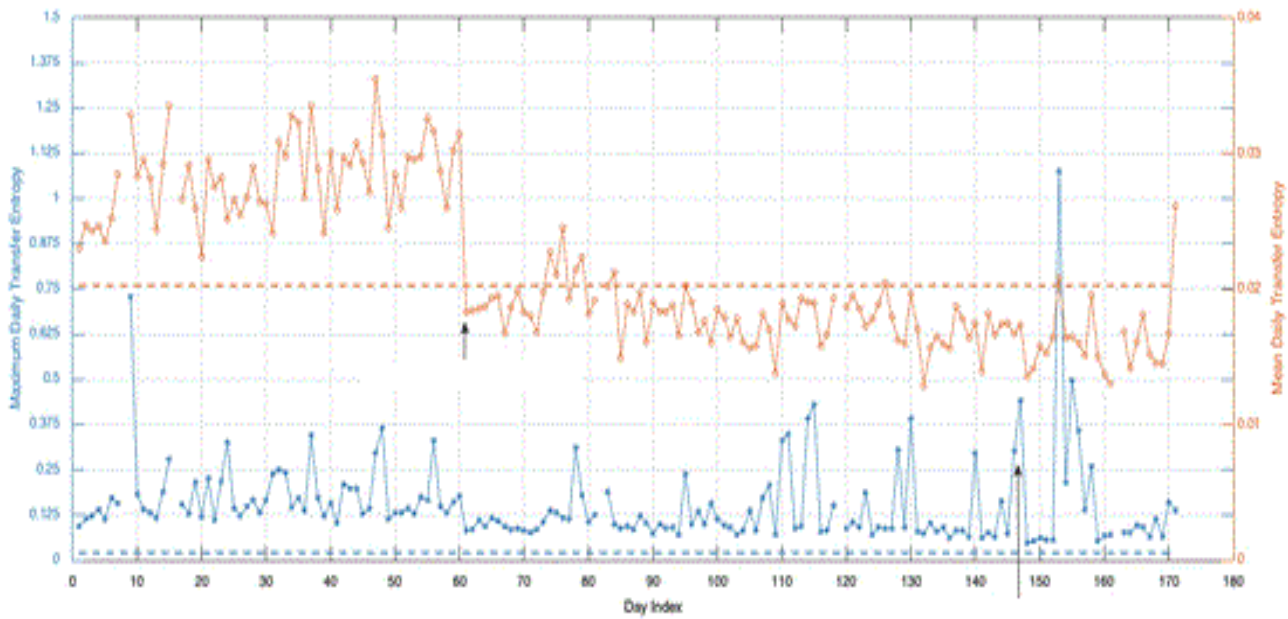

Figure 7. Mean transfer entropy or average transmitted Dow Jones index information

Regarding the Dow Jones index, it should be noted that entropy measurements indicate that some protection measures must be taken when comparing simple systems with data from real complex systems. As Dow Jones' entropy increases, what may be described as the first step, as this issue has been studied in complex systems, the transition is step-by-step, but it is certainly created with a decrease in rising prices on the New York Stock Exchange. 


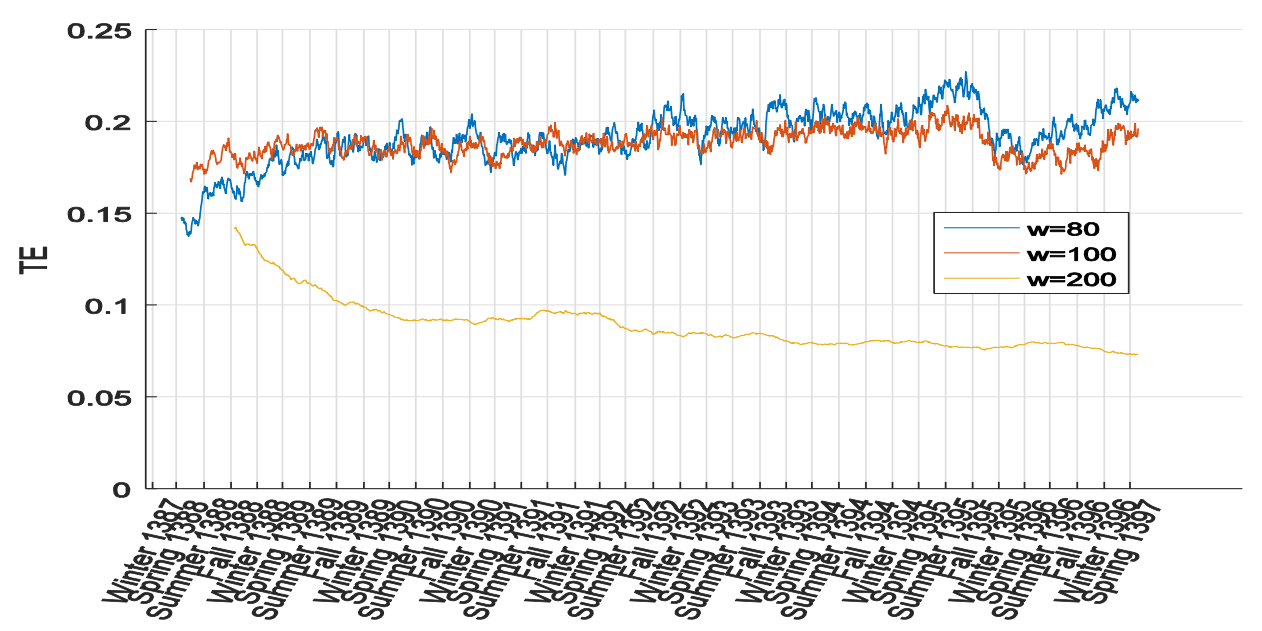

Figure 8. Time series Average information transmitted along with different scales for 180 companies in the Tehran stock market.

The following figure shows the average transfer entropy for 180 companies in the Iranian stock market over time. The marked rectangles indicate the crisis intervals or a drop in the total index of the Tehran Stock Exchange after adjusting for inflation. The mean transfer entropy seems to be more random behavior. That is, the declines observed in it do not correspond to the periods of crisis in the stock market. It seems that although the transfer entropy can be a good indicator to determine the period of crisis in the US Dow Jones group, but cannot be an indicator to determine the crisis for the Tehran Stock Exchange market.

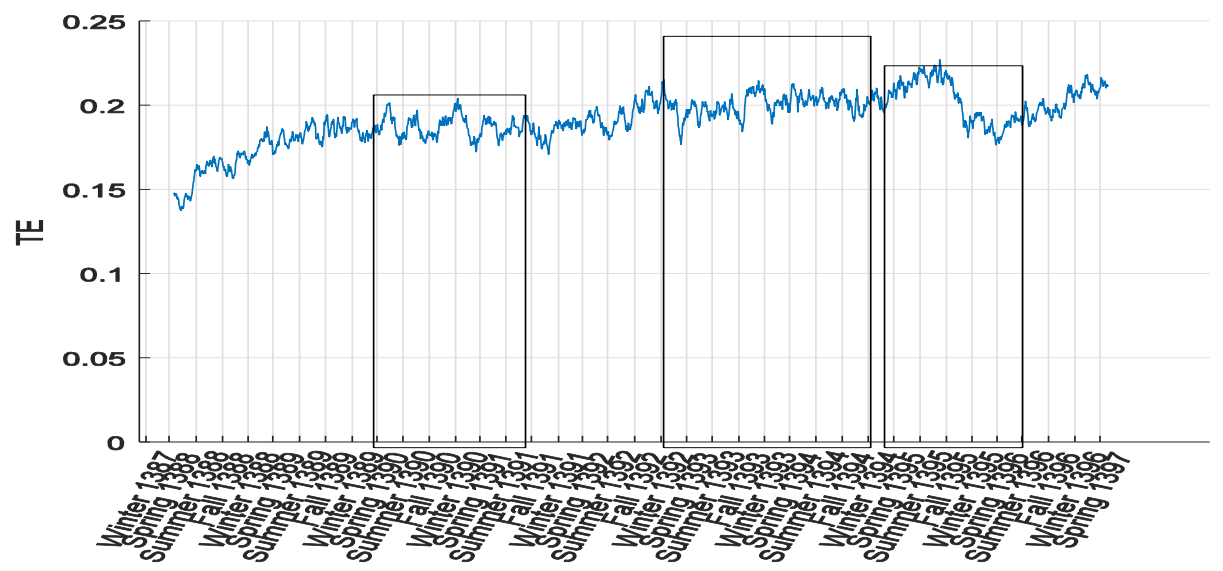

Figure 9. The average transfer entropy per 180 companies on the Tehran Stock Exchange 


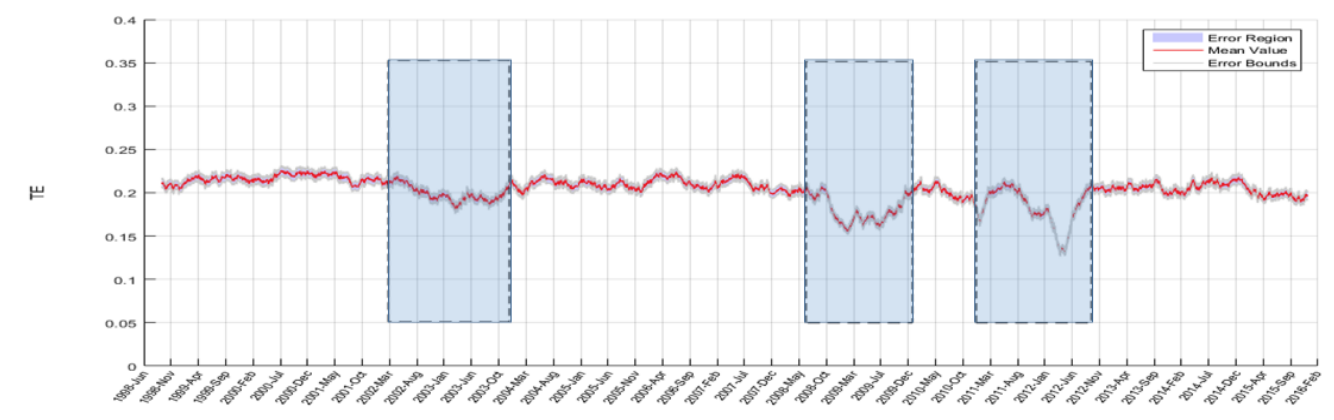

Figure 10.The average transfer entropy for the Dow Jones market

\section{Conclusion and Suggestions}

In general, the occurrence of a financial crisis in stock markets is inevitable, as the experience of these markets around the world confirms this fact. Since the global crash of markets in 2008 studies on crises have been significantly growing. Concerning the Iran Stock Exchange market causality relation between indices and the role of transfer, entropy has been investigated by Osoolian et al. (2019). Yet the ability of the transfer entropy to indicate financial crises has been lacking.

In general, entropic analysis is a new field in financial markets and there is a wide range of applications for entropic analysis in the markets. Despite expectations, our analysis indicates that the transfer entropy is not suitable for the data of the Tehran Stock Exchange. In fact, the analysis on the Tehran Stock Exchange showed that the average transfer entropy for 180 companies in the Tehran Stock Exchange represents random behavior. That is, the declines observed in it do not correspond to the periods of crisis in the stock market. This is while the average transfer entropy for stocks in the Dow Jones group noticeably declines over crises of the US stock market. Such observation suggests further investigation to find the origins of such difference. This is a critical investigation since information plays a key role to form market efficiency.

Funding: This research received no external funding. 


\section{References}

Abdollahzadeh, Salam, Faghandoust Haghighi, Kambiz, Arad, Hamed. (2013). Entropy Investigation of Financial Statements and their Impact on Profit Changes in Tehran Stock Exchange Industries, 13 (52), 133-93. (in Persian).

Abdollahzadeh, Salam, Mohammadi Moqarrani, Atallah, Noroush, Iraj, Amini, Peyman. (2018). Investigating the Impact of Liquidity and Leverage Entropy Rates on Identifying Suspected Firms in Financial Reporting. Audit knowledge. 18 (72). 96-79. (in Persian).

An international trading Broker (2018). A Network Analysis of Global BankingJ Finance. Stab. 9, 168-184.

Arab Salehi, Mehdi, Rahrodi Djerjerdi, Alireza, Hamidian, Narges. (2015). Investigating the Causes of Global Financial Crisis Occurrence and Dissemination with Emphasis on Complexity Approach. Accounting Research, 5 (3), 31-50. (in Persian).

Ardalan kia J. Osoolian M. haven E. Jafari (2020) scaling features of price-volume cross-correlation .research gate

Biani, Azra, Mohammadi, Timur. (2019). Factors Affecting Financial Crises: A Bayesian Averaging Approach. Journal of Quantitative Economics, 16 (2), 180-150. (in Persian).

Babecký, J., T. Havránek, J. Matějů, M. Rusnák, K. Šmídová \& B. Vašíček. (2012). Leading Indicators of Crisis Incidence: Evidence from Developed Countries. Czech National Bank, mimeo.

Bonis, R.D., A. Giustiniani \& G. Gomel. (1999). Crises and Bail Outs of Banks and Countries: Linkages, Analogies, and Differences. The World Economy, Vol. 22, pp: 55-86.

Castrén, O.; Rancan, M (2013). Macro-Networks: An Application to the Euro Area Financial Accounts; ECB Working Paper No. 1510; European Central Bank: Frankfurt am Main, Germany.

Fama, E. F. The behavior of stock-market prices. J. Business 38, 34-105,

Fama, E. F. (1970). Efficient capital markets: a review of theory and empirical work. J. Finance 25, 383-417.

Fosberg, R, (2012), Capital Structure and Financial Crises, working paper, William Paterson University. 
Fatemi Adel, Sorting Univariate Distributions by Entropy and Variance (2001). Master of Science Degree in Mathematics and Statistics, Tehran University of Teacher Education. (in Persian).

Hasanzadeh, Ali and Mehran Kianvand. (2009). The Global Financial Crisis, The OPEC World Oil and Strategic Market, Economic News, New Volume, Seventh Year, No. 126. (in Persian).

Hale, G. (2012). Bank Relationships, Business Cycles, and Financial Crises. J. Int. Econ. 88, 312-325.

Jegadeesh, N. \& Titman, S. (1993). Returns to buying winners and selling losers: Implications for stock market efficiency. The Journal of finance $48,65-91$

Lee, D., \& Park, H. (2019). Measuring Global Financial Linkages: A Network Entropy Approach. Sustainability, 11(17), 4691.

Lo, A. W. \& Mackinlay, A. C. (1990). When Are Contrarian Profits Due to Stock Market Overreaction? Rev. Financial Stud. 3, 175-205.

Mantegna, R. N. \& Stanley, H. E. (2000). An Introduction to Econophysics, Chapter 5,

Namaki A. Ardalan kia J, Hedayatifar. Hosseini A, Jafari G (2020). Analysis of the global banking network by random matrix theory. Cornell University

Osoolian, Mohammad,; Hosseini Esfidavajani, Seyyed Ali \& Bagheri Mobina (2019). Stock market index analysis with entropy approach. Journal of Financial Management Perspective. 8(4), 159-180. (In Persian).

Reinhart, C. M. \& K. S. Rogoff. (2009). This Time is Different. New Jersey: Princeton University Press.

Rummel, C. (2017). Governor's School for Science \& Mathematics, Transfer Entropy within the Nasdaqe Stock Exchange, South Carolina Junior Academy of Science. 76. Schreiber T., Phys. Rev. Lett., 85 (2000) 461.

Shannon, Claude E. (1948). A Mathematical Theory of Communication; Bell System Technical Journal 379-423.

Soheili, Kiomars and Azar Mirzaei Rashno. (2012). Investigating the Relationship between the Global Financial Crisis and Economic Growth in Iran, M.Sc. in Economics, Razi University of Kermanshah. (in Persian).

Sensoy, A., Sobaci, C., Sensoy, S., \& Alali, F. (2014). Effective transfer 
entropy approach to information flow between exchange rates and stock markets. Chaos, Solitons \& Fractals, 68, 180-185.

Stosic, D., Stosic, D., Ludermir, T., de Oliveira, W., \& Stosic, T. (2016). Foreign exchange rate entropy evolution during financial crises. Physica A: Statistical Mechanics and Its Applications, 449, 233-239.

Thomas Schreiber, T., (2000). Measuring Information Transfer, Physical review letters 85(2), 461. Upper, C.; Worms, A. Estimating Bilateral Exposure.

Wiener, Norbert (1949). Extrapolation, Interpolation, and Smoothing of Stationary Time Series. New York: Wiley.

Weistro_er, C. Mobert, .J. (2010). Monitoring Cross-Border Exposure: A Primer on how to Exploit the BIS Banking Statistics; Deutsche Bank Research Current Issues; Deutsche Bank Research: Frankfurt am Main, Germany.

\section{Bibliographic information of this paper for citing:}

Mohaghegh, Arefeh; Hamidian, Mohsen; Hosseiny Esfidvajani, Seyed Ali \& Jafari, Gholamreza (2021). Investigating the financial crisis of the Tehran Stock Exchange using the entropy method of transfer and comparing it with the US financial market. Iranian Journal of Finance, 5(3), 1-16.

Copyright $@$ 2021, Arefeh Mohaghegh, Mohsen Hamidian, Seyed Ali Hosseiny Esfidvajani and Gholamreza Jafari 